\title{
Severe respiratory failure in the course of coronavirus disease 2019 treated with extracorporeal membrane oxygenation
}

\author{
Piotr Suwalski ${ }^{*}$, Andrzej Rydzewski2*, Rafał Wójtowicz³, Dominik Drobiński , Jerzy Walecki,7, Waldemar Wierzba6,7 \\ 1 Clinical Department of Cardiac Surgery, Centre of Postgraduate Medical Education, Warsaw, Poland \\ 2 Department of Internal Medicine, Nephrology and Transplantation Medicine, Centre of Postgraduate Medical Education, Warsaw, Poland \\ 3 Department of Anesthesiology and Intensive Care, Central Clinical Hospital of the Ministry of the Interior and Administration, Warsaw, Poland \\ 4 Department of Cardiac Surgery, Centre for Extracorporeal Therapies, Central Clinical Hospital of the Ministry of the Interior and Administration, Warsaw, Poland \\ 5 Department of Radiology, Centre of Postgraduate Medical Education, Warsaw, Poland \\ 6 University of Humanities and Economics in Łódź, Satellite Campus in Warsaw, Warsaw, Poland \\ 7 Central Clinical Hospital of the Ministry of Interior and Administration, Warsaw, Poland
}

\section{Correspondence to:}

Prof. Andrzej Rydzewski, MD, PhD, Department of Internal Medicine, Nephrology and Transplantation Medicine, Centre of Postgraduate Medical Education, Central Clinical Hospital of the Ministry of the Interior and Administration, ul. Wołoska 137, 02-507 Warszawa, Poland, phone: +48225081200, email: arydzewski@cmkp.edu.pl Received: April 24, 2020.

Revision accepted: June 13, 2020. Published online: June 20, 2020. Kardiol Pol. 2020; 78 (9): 913-915 doi:10.33963/KP.15444

Copyright by the Author(s), 2020

* PS and AR contributed equally to this work.
Introduction The coronavirus disease 2019 (COVID-19) pandemic is a global threat. In most cases, patients develop mild symptoms and recover completely. Mortality due to COVID-19 is estimated to range between $0.99 \%$ and $3.4 \%$, and significantly higher rates are observed in older age groups. It increases from $0.32 \%$ in individuals younger than 60 years of age to $6.4 \%$ in those aged 60 years or older, and up to $13.4 \%$ in those aged 80 years or older. Other risk factors include hypertension, diabetes, chronic obstructive pulmonary disease, cardiovascular disease, and cerebrovascular disease. ${ }^{1}$ Death is usually caused by severe respiratory insufficiency. While over $95 \%$ of people in Europe who died of COVID-19 were over 60 years old, some young people suffer from the devastating effects of the disease.

At present, the role of extracorporeal membrane oxygenation (ECMO) in the management of COVID-19-related severe respiratory failure remains unclear. The World Health Organization interim guidance recommends the following approach in "adult and pediatric patients with ARDS that fail lung protective ventilation strategy": "In settings with access to expertise in extracorporeal membrane oxygenation (ECMO), consider referral of patients with refractory hypoxemia despite lung protective ventilation."

Reports on the use of ECMO in COVID-19 are scarce. In this study, we report the case of a 36-year-old man who was treated with ECMO for severe respiratory insufficiency in the course of COVID-19 and compare it with other cases described in the literature.

Methods Search strategy A systematic search for articles on the use of ECMO in patients with COVID-19 was performed in the PubMed database on April 19, 2020 (Supplementary material). Only studies that reported the number of deaths were included. The identified studies were additionally analyzed by citation tracking to look for further eligible articles.

Statistical analysis Categorical variables were presented as frequency and percentages. $\mathrm{Pa}$ tient informed consent to participate was not required for this study.

Results and discussion A 36-year-old Caucasian man was admitted to the Department of Internal Medicine, Nephrology and Transplantation Medicine because of fever, dyspnea, malaise, nonproductive cough that started 6 days earlier, and 1-day diarrhea. He reported close contact with a person who later tested positive for severe acute respiratory syndrome coronavirus 2 (SARS-CoV-2) that occurred 12 days before presentation. Due to high fever, he was taking over the counter drugs including metamizole, acetaminophen, and ibuprofen.

The patient was a professional driver and a bodybuilder, but he denied using anabolic 
TABLE 1 Studies reporting on extracorporeal membrane oxygenation use in patients with acute respiratory distress syndrome due to coronavirus disease 2019

\begin{tabular}{|c|c|c|c|}
\hline Study & ECMO, n & ECMO survivors, $n(\%)$ & Remarks \\
\hline Bemtgen et $\mathrm{al}^{5}$ & 1 & $1(100)$ & Percutaneous ventricular assist device implantation \\
\hline Hartman et al ${ }^{6}$ & 1 & $1(100)$ & - \\
\hline Li et $\mathrm{al}^{7}$ & 8 & $3(37.5)$ & 1 patient still on ECMO \\
\hline Ruan et al ${ }^{8}$ & 7 & 0 & - \\
\hline \multirow[t]{2}{*}{ Tavazzi et al9 ${ }^{9}$} & 1 & $1(100)$ & $\begin{array}{l}\text { Acute cardiac injury due to presence of the virus in } \\
\text { myocardium }\end{array}$ \\
\hline & & & The patient survived ECMO but later died of sepsis \\
\hline Wu et al ${ }^{10}$ & 1 & 0 & - \\
\hline Yang et al ${ }^{11}$ & 6 & $1(16.7)$ & The survivor still on ECMO at the end of the study \\
\hline \multirow[t]{2}{*}{ Zeng et al ${ }^{12}$} & 12 & $3(25)$ & 5 patients died \\
\hline & & & $\begin{array}{l}4 \text { patients were still alive on ECMO, so the survival rate } \\
\text { may be higher. }\end{array}$ \\
\hline Zhan et al ${ }^{13}$ & 1 & $1(100)$ & - \\
\hline Zhang et al ${ }^{14}$ & 10 & $2(20)$ & $\begin{array}{l}2 \text { patients were discharged, } 3 \text { died, and } 5 \text { were still on } \\
\text { ECMO at the end of the study. }\end{array}$ \\
\hline Zhou et al ${ }^{15}$ & 3 & 0 & - \\
\hline Present study & 1 & 0 & - \\
\hline
\end{tabular}

Abbreviations: ECMO, extracorporeal membrane oxygenation

steroids. He was a single, smoked 1 pack of cigarettes a day, and drunk moderately. Apart from that, he had a history of allergy to penicillin.

On physical examination, his body temperature was $39.6{ }^{\circ} \mathrm{C}$; blood pressure, $140 / 87 \mathrm{~mm} \mathrm{Hg}$; pulse, $110 \mathrm{bpm}$; respiratory rate, 25 breaths per minute; and oxygen saturation, $98 \%$ on ambient air. His Modified Early Warning Score was 3. Fine crackles were heard over the entire chest. The physical examination was otherwise unremarkable.

The patient's laboratory parameters are presented in Supplementary material, Table S1. Notably, he had lymphocytopenia, high levels of lactate dehydrogenase, $C$-reactive protein, and procalcitonin, and tested positive for SARS-CoV-2 by reverse transcriptase-polymerase chain reaction. He also tested positive for hepatitis $C$ (he was unaware of his hepatitis $C$ virus status).

The first chest X-ray performed on admission showed massive bilateral pulmonary consolidations in the peripheral and lower areas and no pleural effusion (Supplementary material, Figure S1).

On hospitalization day 1 , his dyspnea increased with oxygen saturation decreasing to $90 \%$ on ambient air. He was treated with oxygen therapy delivered by a mask, levofloxacin, hydroxychloroquine (hydroxychloroquine was part of a standard hospital protocol based on the recommendations of the Polish Society of Epidemiology and Infectious Diseases), and paracetamol. Despite treatment, the patient's condition deteriorated on the second day of hospitalization (oxygen saturation with oxygen delivered by a mask was $88 \%$ ) and he was transferred to the intensive care unit in our hospital. Meropenem, azithromycin, vancomycin, and lopinavir / ritonavir were added, and levofloxacin was discontinued. In the intensive care unit, the patient was intubated and received mechanical ventilation in the pressure-synchronized intermittent mandatory mode. Alveolar recruitment maneuvers and intermittent prone positioning were also used. Chest computed tomography on hospitalization day 5 demonstrated massive bilateral consolidations with peripheral areas of ground-glass opacities, the crazy paving sign (particularly in the subpleural area), and bilateral pleural effusion (Supplementary material, Figure S2).

Due to further respiratory deterioration and worsening condition, a decision was made to put the patient on ECMO on hospitalization day 8. Veno-venous ECMO was instituted percutaneously following bedside ultrasound examination of femoral vessels. A $23 \mathrm{~F}$ drainage cannula was inserted through the right femoral vein and a $21 \mathrm{~F}$ return cannula through the right jugular vein. These were subsequently connected with tubes to the console (Cardiohelp System, Getinge, Germany). Protective mechanical ventilator settings were used as the pressure control mode with peak pressure decreased to $20 \mathrm{~cm} \mathrm{H}_{2} \mathrm{O}$, a fraction of inspired oxygen of 0.6 , a positive end-expiratory pressure of $10 \mathrm{~cm} \mathrm{H}_{2} \mathrm{O}$, and an inspiratory-to-respiratory ratio of 2:1. Lung compliance in this case was critically low. 
Despite the use of various ventilation modes, the respiratory volume did not exceed $100 \mathrm{ml}$. Oxygen saturation was monitored continuously. Packed red blood cells and fresh frozen plasma were transfused when needed. Kidney function remained normal during the course of the disease, and small, left-sided peumothorax occurred on hospitalization day 5. Unfortunately, the disease deteriorated and the patient died of severe pneumonia, septic shock, and respiratory failure on hospitalization day 12 .

The idea behind the use of veno-venous ECMO in patients suffering from acute respiratory distress syndrome (ARDS) and refractory hypoxemia is that it promotes lung recovery by enabling protective ventilation techniques and, thus, saving the lungs from injury related to mechanical ventilation.

The ECMO procedure may induce lymphocyte depletion, which is common in COVID-19 and portends poor prognosis. However, we did not observe worsening lymphopenia after ECMO institution in our patient. We had also been wondering whether hepatitis $C$ and possible anabolic steroid use might have been a factor predisposing to a severe course of the disease, although liver disease was not suggested to be a risk factor before. ${ }^{1}$

By PubMed search, we identified 11 papers describing a total of 51 patients. ${ }^{5-15}$ These data presented in TABLE 1 (including our case) suggest that the mortality rate in adult patients with COVID-19 on ECMO is about $75 \%$. This value is similar to that reported for COVID-19 patients treated with ECMO, ${ }^{3}$ as well as in an observational, retrospective study of patients receiving ECMO and suffering from severe infections. ${ }^{4}$ Whereas total in-hospital mortality reported in the latter study was $72 \%$, the survival rate was much higher for community-acquired infections and for patients who were treated with ECMO within the first 4 days of hospitalization, which may suggest a similar early approach in COVID-19.

In this short communication, we described a case of a young man with severe COVID-19 who died despite treatment with ECMO. We also reviewed studies reporting on ECMO use in patients with ARDS due to COVID-19.

\section{SUPPLEMENTARY MATERIAL}

Supplementary material is available at www.mp.pl/kardiologiapolska.

\section{ARTICLE INFORMATION}

CONFLICT OF INTEREST None declared.

OPEN ACCESS This is an Open Access article distributed under the terms of the Creative Commons Attribution-NonCommercial-NoDerivatives 4.0 International License (CC BY-NC-ND 4.0), allowing third parties to download articles and share them with others, provided the original work is properly cited, not changed in any way, distributed under the same license, and used for noncommercial purposes only. For commercial use, please contact the journal office at kardiologiapolska@ptkardio.pl.

HOW TO CITE Suwalski P, Rydzewski A, Wójtowicz R, et al. Severe respiratory failure in the course of coronavirus disease 2019 treated with extracorporeal membrane oxygenation. Kardiol Pol. 2020; 78: 913-915. doi:10.33963/KP.15444

\section{REFERENCES}

1 Sławiński G, Lewicka E. What should a cardiologist know about coronavirus disease 2019? Kardiol Pol. 2020; 78: 278-283.

2 World Health Organization. Clinical management of severe acute respiratory infection when COVID-19 is suspected. Interim guidance. 13 March 2020. https:// www.who.int/publications-detail/clinical-management-of-severe-acute-respiratory-infection-when-novel-coronavirus-(ncov)-infection-is-suspected. Accessed April 4, 2020.

3 Ñamendys-Silva SA. ECMO for ARDS due to COVID-19. Heart Lung. 2020; 49: 348-349.

4 Cheng A, Sun HY, Tsai MS, et al. Predictors of survival in adults undergoing extracorporeal membrane oxygenation with severe infections. J Thorac Cardiovasc Surg. 2016; 152: 1526-1536.

5 Bemtgen X, Krüger K, Supady A, et al. First successful treatment of COVID-19 induced refractory cardiogenic plus vasoplegic shock by combination of PVAD and ECMO - a case report. ASAIO J. 2020; 66: 607-609.

6 Hartman ME, Hernandez RA, Patel K, et al. COVID-19 respiratory failure: targeting inflammation on VV-ECMO support. ASAIO J. 2020; 66: 603-606.

7 Li X, Guo Z, Li B, et al. Extracorporeal membrane oxygenation for coronavirus disease 2019 in Shanghai, China. ASAIO J. 2020; 66: 475-481.

8 Ruan $\mathrm{Q}$, Yang K, Wang W, et al. Clinical predictors of mortality due to COVID-19 based on an analysis of data of 150 patients from Wuhan, China. Intensive Care Med. 2020; 46: 846-848.

9 Tavazzi G, Pellegrini C, Maurelli M, et al. Myocardial localization of coronavirus in COVID-19 cardiogenic shock. Eur J Heart Fail. 2020; 22: 911-915.

10 Wu C, Chen $X$, Cai $Y$, et al. Risk factors associated with acute respiratory distress syndrome and death in patients with Coronavirus disease 2019 pneumonia in Wuhan, China. JAMA Intern Med. 2020; 180: 1-11.

11 Yang $X, Y u Y, X u$ J, et al. Clinical course and outcomes of critically ill patients with SARS-CoV-2 pneumonia in Wuhan, China: a single-centered, retrospective, observational study. Lancet Respir Med. 2020; 8: 475-481.

12 Zeng $Y$, Cai Z, Xianyu $Y$, et al. Prognosis when using extracorporeal membrane oxygenation (ECMO) for critically ill COVID-19 patients in China: a retrospective case series. Crit Care 2020; 24: 148.

13 Zhan WQ, Li MD, Xu M, Lu YB. Successful treatment of COVID-19 using extracorporeal membrane oxygenation, a case report. Eur Rev Med Pharmacol Sci. 2020; 24: 3385-3389.

14 Zhang G, Hu C, Luo L, et al. Clinical features and short-term outcomes of 221 patients with COVID-19 in Wuhan, China. J Clin Virol. 2020; 127: 104364.

15 Zhou F, Yu T, Du R, et al. Clinical course and risk factors for mortality of adult inpatients with COVID-19 in Wuhan, China: a retrospective cohort study. Lancet. 2020; 395: 1054-1062. 